\title{
ESTUDO RETROSPECTIVO DA OCORRÊNCIA DE FALHAS REPRODUTIVAS EM VACAS LEITEIRAS
}

Vitor Lemes Silva, Flávio Henrique de Paula, Aline Sousa Camargos, Jeferson Corrêa Ribeiro, Andreia Santos Cezário, Wallacy Barbacena Rosa Dos Santos

Instituto Federal Goiano, Departamentos de Informática e Zootecnia, Morrinhos, GO. E-mail: vitorlemes18@hotmail.com

\section{RESUMO}

Para a adequação da atividade leiteira, é de fundamental importância a determinação de uma produção mais rentável com o uso intensivo da área para a produção de forragem, um controle da eficiência reprodutiva e menor idade ao primeiro parto. Este estudo objetivou quantificar a ocorrência de abortos e natimortos em vacas leiteiras nas fazendas São Caetano e Chapadão no munícipio de Morrinhos-Go. 0 acompanhamento das falhas reprodutivas foi feito diariamente durante seis anos, de 2008 a 2013 . 0 técnico responsável pelo setor registrava as ocorrências nas agendas de escrituração zootécnica das fazendas. Em 2014, os dados foram recuperados dos arquivos das fazendas e lançados em planilha digital. Para a análise estatística, as variáveis das taxas de aborto e natimorto (\%) foram submetidas à análise de variância, ao nível de significância de $5 \%$, tendo como causa de variação o ano. A taxa de aborto observada foi $3,93 \%$ e a taxa de natimortalidade $2,89 \%$ ambas consideradas baixas. Não houve diferença significativa entre os anos acompanhados ( $p<0,05$ ) em ambos. A natimortalidade e o aborto não são considerados problemas nas fazendas estudadas, devido às boas práticas de controle e manejo.

Palavras-chave: aborto; natimorto e pecuária.

\section{RETROSPECTIVE STUDY OF REPRODUCTIVE FAILURE OCCURRENCE IN DAIRY COWS}

\begin{abstract}
For the adequacy of the milk activity, it is of fundamental importance to determine a more profitable production with the intensive use of the area for the production of forage, a control of the reproductive efficiency and lower age at the first calving. This study aimed to quantify the occurrence of abortions and stillbirths in dairy cows in the São Caetano and Chapadão farms in the town of Morrinhos-Go. The monitoring of reproductive failures was done daily for six years, from 2008 to 2013. The technician responsible for the sector recorded the occurrences in the agricultural bookkeeping agendas of the farms. In 2014, the data were retrieved from the farm files and released on a digital spreadsheet. For the statistical analysis, the variables of the abortion and stillbirth rates (\%) were submitted to analysis of variance, at a significance level of $5 \%$, having as cause of variation the year. The observed abortion rate was $3.93 \%$ and the stillbirth rate $2.89 \%$ both considered low. There was no significant difference between the years followed $(p<0.05)$ in both. Stillbirth and abortion are not considered problems in the farms studied, due to the good practices of control and management.
\end{abstract}

Keywords: Abortion; Stillbirth and livestock.

\section{INTRODUÇÃo}

A sanidade do rebanho é extremamente importante para o sucesso reprodutivo. As doenças influenciam diretamente na taxa de fertilização e concepção das fêmeas bovinas (VANROOSE et al., 2000; JESUS, 2001). Conseguir detectar infecções tanto nos machos quanto nas fêmeas de maneira isolada, podem diminuir significativamente o contágio da população.
Segundo Dunne et al. (2000), Diskin e Morris (2008), as taxas de fertilização são relativamente altas, variando de 80 a $90 \%$ em rebanhos. Em situações de falta de controle sobre esses fatores sanitários, essas taxas podem cair bruscamente para valores insatisfatórios e de difícil controle.

A abertura para o mercado internacional aumentou a concorrência, mas em compensação criou exigências em relação a maior 
produtividade e melhor qualidade nos produtos comercializados. O segmento da bovinocultura foi martirizado durante muito tempo por questões sanitárias que barraram as exportações. Fator que objetivou a especialização dos sistemas de criação, possibilitando o aumento da produção de leite e de carne, sendo hoje considerada uma das explorações de maior importância econômica Dirksen e Stober, 1981; Ramos et al., 2001).

A inseminação artificial estabeleceu-se como ferramenta de aumento da eficiência reprodutiva, pelo avanço do melhoramento genético e por possibilitar o menor uso de monta natural e custo com touros. E permitiu a utilização de animais de reposição com maior mérito genético (ASBIA, 2010).

$O$ sucesso da inseminação vem se espalhando, criando força e mostrando os resultados satisfatórios que determinam o seu reconhecimento como ferramenta produtiva de grande valor para a atividade tanto de leite como de corte e até de outras espécies produtivas como suínos, caprinos, equinos, dentre outros. Com a inseminação, vários problemas de falhas na reprodução foram resolvidos, mas ainda temse uma grande dificuldade devido aos fatores biológicos e ambientais que caracterizam em porcentagem de 5 a $20 \%$ de deficiência na cadeia produtiva, resultante em perdas econômicas.

As perdas reprodutivas são as causas responsáveis pela queda econômica para os produtores de bovinos independente da finalidade produtiva a nível mundial (DUNNE et al., 2000; BERG et al., 2010).

Os modelos nacionais de produção de leite baseados na média de litros/hectare/ano ou muitas vezes na produção por vaca/ano, os fatores de mau desempenho reprodutivo, inferior qualidade genética nos quesitos produção, duração e persistência de lactação, são os fatores responsáveis pela baixa produtividade dos rebanhos leiteiros (WOLF, 2003).

É preciso conhecer a frequência de abortos e natimortos na localidade antes de iniciar pesquisas e programas de controle. Deste modo, o presente trabalho teve por objetivo estudar a ocorrência de abortos e natimortos em bovinos leiteiros de alta produção.

\section{MATERIAL E MÉTODOS}

$O$ estudo foi conduzido nas fazendas de alta produção leiteira São Caetano e Chapadão, no município de Morrinhos-Go com produção média de 11.617 mil litros de leite/dia em sistemas de produção de leite a pasto com suplementação e sistema free-stall para os animais da raça holandesa.

O Município apresenta latitude $S 17^{\circ} 43^{\prime}$ $52^{\prime \prime}$ e longitude W $49^{\circ} 05^{\prime} 58^{\prime \prime}$, na região CentroOeste com altitude 771 metros, caracterizado por verões quentes e úmidos e média térmica anual 25으.

A ocorrência de abortos e natimortos foi observada nas fêmeas em reprodução das raças Girolando, Jersey e Holandês em vários graus de sangue, acima dos 30 meses de idade, criadas em sistema a pasto (com ciclos estrais regulares), vacinadas contra as principais enfermidades conforme exigência do MAPA (Ministério da Agricultura Pecuária e Abastecimento) são elas a brucelose, aftosa e raiva.

O manejo reprodutivo observado em ambas as propriedades incluía monta natural ou inseminação artificial das matrizes, com observação de cio e inseminação artificial em tempo fixo.

Foi considerado aborto a interrupção de gestação, anteriormente diagnosticada via palpação transretal ou ultrassonografia por médico veterinário, com expulsão do feto. $E$ natimorto o bezerro que nasceu morto após 260 dias de gestação, previamente confirmada e acompanhada por médico veterinário.

O acompanhamento foi feito diariamente durante seis anos, de 2008 a 2013. O técnico responsável pelo setor registrava as ocorrências nas agendas de escrituração zootécnica das fazendas. Em 2014, os dados foram recuperados dos arquivos das fazendas e lançados em planilha digital.

Para a análise estatística, as variáveis das taxas de aborto (\%) e de natimortos (\%) foram submetidas à análise de variância, ao nível de significância de 5\% (SAS, 2013), tendo como causa de variação o ano.

\section{RESULTADOS E DISCUSSÃO}

As taxas de abortos observadas não foram significativas $(p<0,05)$, sendo a porcentagem média total no período 3,93\% (conforme observado na Tabela 1).

Santos e Vasconcelos (2009), observaram pequena taxa de abortamento é usualmente observada em fazendas leiteiras. A ocorrência de 3 a 5 abortamentos a cada 100 gestações é considerada normal.

Mesmo com o aumento do número de animais ao longo dos anos, a porcentagem de abortos a mesma 
proporcionalmente ao número de fêmeas em atividade reprodutiva no rebanho estudado. Ainda segundo Santos e Vasconcelos (2009), uma das possíveis causas de aborto em fêmeas bovinas está relacionada a agentes infeciosos, mas outros fatores como alterações genéticas, estresse térmico e agentes tóxicos podem estar envolvidos.

Tabela 1. Ocorrência de abortos em granjas leiteiras de alta produção ao longo de seis anos

\begin{tabular}{cccc}
\hline Ano & Total de abortos & $\begin{array}{c}\text { No de vacas em } \\
\text { reprodução }\end{array}$ & \% de abortos \\
\hline 2008 & 6 & 186 & $3,23 \%$ \\
2009 & 8 & 210 & $3,81 \%$ \\
2010 & 19 & 365 & $5,20 \%$ \\
2011 & 13 & 374 & $3,48 \%$ \\
2012 & 20 & 399 & $5,01 \%$ \\
2013 & 13 & 459 & $2,83 \%$ \\
\hline Total & 79 & 1993 & $3,93 \%$ \\
\hline
\end{tabular}

A taxa de natimortos observada não foi significativa, sendo percentual médio total de 2,89\% (conforme observado na Tabela 2). Mesmo com o aumento do número de animais ao longo dos anos, a porcentagem de natimortos permaneceu sem diferença, proporcionalmente ao rebanho $(p<0,05)$.

Tabela 2. Ocorrência de natimortos em granja leiteira de alta produção ao longo de seis anos

\begin{tabular}{cccc}
\hline Ano & Total de natimortos & Total de partos & $\%$ de natimortos \\
\hline 2008 & 3 & 189 & $1,59 \%$ \\
2009 & 9 & 236 & $3,81 \%$ \\
2010 & 14 & 380 & $3,68 \%$ \\
2011 & 5 & 366 & $1,37 \%$ \\
2012 & 17 & 416 & $4,09 \%$ \\
2013 & 12 & 487 & $2,46 \%$ \\
\hline Total & 60 & 2074 & $2,89 \%$ \\
\hline
\end{tabular}

O manejo intensivo ao qual as vacas de alta aptidão leiteira são submetidas pode favorecer a transmissão de várias enfermidades infecciosas (MÉDICl et al., 2000). E as principais causas para histórico de natimortalidade em um rebanho são relacionadas a doenças infecciosas (CAMPOS, 2009). Durante o período deste estudo, foi observado um rígido controle sanitário do rebanho e maternidade.

A presença de maternidade na propriedade leiteira facilita o acompanhamento e alguma interferência que se faça necessária no decorrer do parto. Em rebanhos nos quais se faz a observação no parto, os problemas são resolvidos de forma mais rápida, com maior sucesso e menor índice de natimortos (BARBOSA et al., 2011).

Meijering (1984) observou maior ocorrência de natimortos e menor registro de distocia no verão em comparação ao inverno, possivelmente relacionado à estabulação dos animais nesse período de inverno, o que permite maior e melhor assistência a qualquer problema.

O número de ciclos reprodutivos da vaca também pode influenciar a taxa de natimortos. As primíparas comumente apresentam produtividade inferior e maior ocorrência de mortalidade de suas crias (SCHMIDEK, 2009).

Ocorreram poucas falhas durante os anos estudados e os motivos são relacionados ao bom manejo nutritivo, reprodutivo, sanitário e um eficiente controle zootécnico adotados em ambas as propriedades.

\section{CONCLUSÃO}

O aborto não é um problema de grande destaque dentro da pecuária leiteira de alta produção do município. A taxa de natimortos observada neste estudo está dentro da faixa aceitável para a pecuária leiteira. 


\section{REFERÊNCIAS}

ASBIA. Relatório estatístico de importação, exportação e comercialização de sêmen. Associação brasileira de inseminação artificial em tempo fixo. 2010. Disponível em: <http://www.asbia.org.br/novo/upload/mercado /relatorio2010.pdf> Acesso em: 15 Out. 2016.

BARBOSA, C.F.; JACOMINI, J.O.; GOMES, E. Inseminação artificial em tempo fixo e diagnóstico precoce de gestação em vacas leiteiras mestiças. Revista Brasileira de Zootecnia, v.40, n.1, p.79-84, 2011. https://doi.org/10.1590/S1516-

$\underline{35982011000100011}$

BERG, D.K.; VAN LEEUWEN, J.; BEAUMONT, S. Embryo loss in cattle between Days 7 and 16 of pregnancy. Theriogenology, v.73, p.250-260, 2010.

https://doi.org/10.1016/j.theriogenology.2009.0 $\underline{9.005}$

CAMPOS, C. Aborto: indique as causas para evitar perdas. Revista Balde Branco, v.4, p.21-25, 2009. Disponível:<http://www.biologico.sp.gov.br/notic ias.php>Acesso em: 24/09/2016.

DISKIN, M.G.; MORRIS, D.G. Embryonic and early foetal losses in cattle and other ruminants. Reproduction in Domestic Animals. v.43, p.260267, 2008. https://doi.org/10.1111/j.1439$\underline{0531.2008 .01171 . x}$

DIRKSEN, G.; STOBER, E.M. As afecções dos bovinos: melhor prevenir que curar. Hora Veterinária, v.1, n.3, p.13-8, 1981.

DUNNE, L.D.; DISKIN, M.G.; SREENAN, J.M. Embryo and foetal loss in beef heifers between day 14 of gestation and full term. Animal Reproduction Science, v.58, p.39-44, 2000. https://doi.org/10.1016/S0378-4320(99)00088-3 JESUS, V.L.T. Risk factors for infectious diseases. Revista Brasileira de Reprodução Animal, Belo Horizonte, v. 25, p. 93-6, 2001.

MEIJERING, A. Dystocia and stillbirth in cattle - a review of causes, relations and implications. Livest Produção Science, v. 11, p. 143-177, 1984. https://doi.org/10.1016/0301-6226(84)90057-5

MÉDICI, K.C.; ALFIERI, A.A.; ALFIERI, A.F. Prevalência de anticorpos neutralizantes contra $O$ herpesvírus bovino tipo 1 , decorrente de infecção natural, em rebanhos com distúrbios reprodutivos. Ciência Rural, v.30, n.2, p.347-350, $2000 . \quad$ https://doi.org/10.1590/S0103$\underline{84782000000200025}$

RAMOS, L.S.; SILVA, L.A.F.; MEIRINHOS M.L.G. Avaliação de parâmetros reprodutivos em Fêmeas bovinas de aptidão leiteira Portadoras de pododermatite necrosante. ARS Veterinária, v.17, n.2, p.98-106, 2001.

SANTOS, R.M.; VASCONCELOS, J.L.M. Abortamento em vacas leiteiras. 2009. Disponível em: <http://www.milkpoint.com.br/radartecnico/repr oducao/abortamento-em-vacas leiteiras 50822n.aspx>

SAS. SAS users guide: statistic. Cary, NC: SAS Institute Inc., 2013.

SCHMIDEK. Variabilidades genética e não genética na mortalidade pré-desmama de bezerros de corte. Revista Unesp, v. 3, p.42-45, 2009.

VANROOSE, G.; KRUIF, A.; VAN SOOM A. Embryonic mortality and embryopathogeninteractions. Animal Reproductive Science, v.60, p.131-43, 2000. https://doi.org/10.1016/S0378-4320(00)00098-1

WOLF, M.C.C. Fatores ambientais sobre a idade ao primeiro parto, dias abertos e intervalo entre partos em vacas da raça holandesa na bacia leiteira de Castrolanda-Estado do Paraná. 2003. 1-4 f. Dissertação (Mestrado) - Universidade Federal do Paraná, Curitiba-PR, 2003.

Recebido para publicação em 15/08/2017

Revisado em 05/12/2017

Aceito em 09/02/2018 